Journal of Zhejiang University-SCIENCE A (Applied Physics \& Engineering)

ISSN 1673-565X (Print); ISSN 1862-1775 (Online)

www.zju.edu.cn/jzus; www.springerlink.com

E-mail: jzus@zju.edu.cn

\title{
Erratum:
}

\section{Erratum to: Mass transfer and reaction kinetics of sulfuryl fluoride absorption with aqueous sodium hydroxide solutions}

\author{
Yong $\mathrm{NIE}^{\dagger 1}$, Xiao-jiang LIANG ${ }^{1}$, Mei-zhen $\mathrm{LU}^{1}$, Feng-wen $\mathrm{YU}^{1}$, Da-yong $\mathrm{GU}^{2}$, Min $\mathrm{MIN}^{3}$, Jian-bing $\mathrm{JI}^{1}$ \\ $\left({ }^{1}\right.$ College of Chemical Engineering, Zhejiang University of Technology, Hangzhou 310014, China) \\ ( ${ }^{2}$ Shenzhen International Travel Health Care Center, Shenzhen 518033, China) \\ $\left({ }^{3}\right.$ Center for Biorefining and Department of Bioproducts and Biosystems Engineering, University of Minnesota, Saint Paul, MN 55108, USA) \\ †E-mail: ny_zjut@zjut.edu.cn
}

doi:10.1631/jzus.A14e0055

Erratum to: J Zhejiang Univ-Sci A (Appl Phys \& Eng) 2014 15(7):540-546 doi:10.1631/jzus.A1400055

The original version of this article unfortunately contained two mistakes. In p. 544, the square root on the right side of Eq. (14) “ $H a=\sqrt{k_{2} D_{\mathrm{A}} /\left(k_{\mathrm{LA}}^{0}\right)^{2} C_{\mathrm{BL}}^{1 / 2}}$ ” and the square root on the right side of Eq. (15) “ $E=H a=\sqrt{k_{2} D_{\mathrm{A}} /\left(k_{\mathrm{LA}}^{0}\right)^{2} C_{\mathrm{BL}}^{1 / 2}}$ ” were incorrect.
The correct versions of Eqs. (14) and (15) are given below:

$$
\begin{aligned}
& H a=\sqrt{k_{2} D_{\mathrm{A}} /\left(k_{\mathrm{LA}}^{0}\right)^{2}} C_{\mathrm{BL}}^{1 / 2}, \\
& E=H a=\sqrt{k_{2} D_{\mathrm{A}} /\left(k_{\mathrm{LA}}^{0}\right)^{2}} C_{\mathrm{BL}}^{1 / 2} .
\end{aligned}
$$

